\title{
Editorial: Pork Pie in the Sky
}

'Stephen Hawking seems to hope that a complete cosmological theory can be produced which will make possible "the ultimate triumph of human reason", namely that "we would know the mind of God"'. This young but famous sentence is quoted in a new book by Mary Midgley, who adds a brief comment: 'It is worth while to remember this kind of remark when we come across the frequently held opinion that hardheaded incredulity is a central part of the scientific character'. On the back cover of Mrs Midgley's book ${ }^{1}$ the publisher announces that:

The package called Science has always included strange and potent myths as well as facts. In the past, a seventeeth-century scientist's fantasy was to be a sexual victor over a prostrate Mother Nature. Today, some prophetic physicists argue that modern technology will enable humanity to colonise space and dominate the whole universe. They offer pie in the sky on a scale seldom approached by the religions. Mary Midgley's latest book examines the meaning of such dreams, the general importance of myth, and the relation of both to Science.

Mrs Midgley herself warns that the pie in the sky could not be pork pie:

That pigs will fly is not just improbable; the skeletal structure of mammals makes it an impossibility. Angels, as traditionally represented in Western art, similarly are not anatomically possible. Again, a human child a year old cannot grow up into an elephant. Accordingly, a biologist who wished to canvass the project of genetically engineering angels or winged pigs or elephant-children would have to start by explaining fully how these objections had been met. The same thing is true of Dyson's offer (which we shall meet shortly) to adapt human beings for outdoor life on Mars.

The author's encompassing theme in these racy Gifford Lectures is the contents of the 'last chapters' where scientists loosen the grip of reason and rise or fall into myth and faith, feeling and fantasy, dream and drama. She knows and shows what confusion spouts from the mingling of such currents. Many others have protested at the ambition of scientists to weave one seamless tapestry of knowledge by the application of something-some one thing-to be honoured as 'scientific

${ }^{1}$ Science as Salvation: A Modern Myth and its Meaning, by Mary Midgley, Routlege, 1992, £25.00. 


\section{Editorial}

method'. Mrs Midgley strikes new notes. She castigates the self-delusion and the 'dead-pan dishonesty' that we must ascribe to some of the apostles of the scientific faith if we are not to ascribe to them a matchless quality and degree of lunacy. She emphasizes more than once the degree to which the intellectual and ethical aberrations of the condemned pundits are motivated by a reckless appetite for power. Some of these ingredients are concentrated into a few lines quoted from J. D. Bernal's The World, the Flesh and the Devil, published in 1929:

Once acclimatized to space-living, it is unlikely that man will stop until he has roamed over and colonized most of the sidereal universe, or that even this will be the end. Man will not ultimately be content to be parasitic on the stars, but will invade them and organize them for his own purposes. . . The stars cannot be allowed to continue in their own way, but will be turned into efficient heat-engines. . . By intelligent organization, the life of the universe could probably be prolonged to many millions of millions of times what it would be without organisation.

At Bernal's end of our century we find J. B. S. Haldane, another Marxist prophet, and H. G. Wells, George Bernard Shaw and Nietzsche-names to guarantee that what is done in the name of science need not be scientific.

Mrs Midgley, as her book proceeds, deals more and more with the comparable figures of our own day: Jacques Monod, Freeman Dyson, Paul Davies, John D. Barrow and Frank J. Tipler. Dyson acknowledges the influence of Bernal, and so do Barrow and Tipler, who write as a team.

Mary Midgley will be accused of being un-scientific and perhaps of being anti-scientific. Her reply must include a reminder that the questions she is dealing with are not scientific questions, but moral and metaphysical and epistemological questions about science.

Mrs Midgley quotes a passage from an article in The Lancet of 1870 , by an unknown Dr J. H. Bennet:

The principal feature which appears to me to characterise the Caucasian race, to raise it immeasurably above all other races, is the power that many of its male members have of advancing the horizons of science, of penetrating beyond the existing limits of knowledge-in a word, the power of scientific discovery. I am not aware that the female members of our race participate in this mental power, in this supreme development of the human mind.

They can write good books of philosophy, including good Gifford Lectures. And that's not pie in the sky. 